
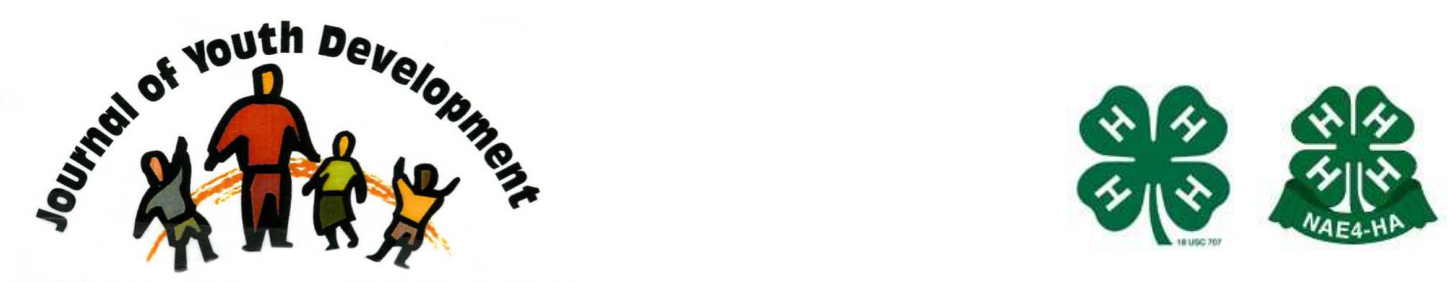

Bridging Research \& Practice

\title{
Measuring the Effectiveness of the Leave No Trace PEAK Program
}

\author{
Jennifer Miller \\ State University of New York at Cortland \\ Eddie Hill \\ Human Movement Sciences Dept. \\ Old Dominion University \\ Norfolk, VA \\ ehill@odu.edu \\ Amy Shellman \\ State University of New York at Cortland \\ Ron Ramsing \\ Western Kentucky University \\ Bowling Green, KY \\ Ben Lawhon \\ Leave No Trace Center for Outdoor Ethics \\ Boulder, CO
}




\title{
Measuring the Effectiveness of the Leave No Trace PEAK Program
}

Jennifer Miller and Amy Shellman

State University of New York at Cortland

Eddie Hill

Old Dominion University

Ron Ramsing

Western Kentucky University

Ben Lawhon

Leave No Trace Center for Outdoor Ethics

\begin{abstract}
The Leave No Trace Center for Outdoor Ethics developed the Promoting Environmental Awareness in Kids (PEAK) program to teach children the seven Leave No Trace principles. The purpose of this study was to assess the effectiveness of the PEAK program. A significant increase was found between the pre-test $(\mathrm{M}=3.41, \mathrm{SD}=.34)$ and the post-test $(\mathrm{M}=3.61, \mathrm{SD}=.36)$ with the post-test scores being significantly higher, $f(1,140)=11.15$, $\mathrm{p}<.01$. No significant difference was found between the pre-test $(\mathrm{M}=3.48, \mathrm{SD}=.35)$, post-test $(\mathrm{M}=3.63, \mathrm{SD}=.35)$, and 8-month post-test $(\mathrm{M}=3.38, \mathrm{SD}=.41)$. The 8 -month post-test indicated a drop in scores, though not statistically significant, below the pretest. Results supported the PEAK program's effectiveness, in the short-term, in teaching children the Leave No Trace principles. However, longer-term retention was not supported.
\end{abstract}

\section{Introduction}

The common statement, "go outside and play," heard by many children growing up for centuries, is now being shouted by a growing number of researchers, educators, and medical professionals. According to the 2010 Special Report on Youth: The Next Generation of Outdoor Champions, participation in outdoor recreation has declined tremendously in two years, 
especially among children between the ages of six and 12 leading to an "unprecedented public health and conservation problem" (The Outdoor Foundation, 2010, p. 4). Between 2006 and 2008, boys participated in 10 percent fewer outdoor activities, while girls' outdoor activity participation declined by 19 percent. This alarming trend has been extensively studied in more recent years to determine why children are spending less time outside (Louv, 2008). Enticing technological advancements, parental fears, and decreasing green spaces, among others, have been identified as reasons children are spending less time out of doors. As efforts are underway to get more children outside, the Leave No Trace Center for Outdoor Ethics developed a kidfriendly program to promote environmental awareness and stewardship of the outdoors.

The Promoting Environmental Awareness in Kids (PEAK) program was created in 2001, and a scale to measure the effectiveness of the program, the PEAK Assessment Scale (PAS) was recently developed (Miller, Shellman, Hill, Ramsing, \& Lawhon, 2012). To understand the impact of the PEAK program, the Leave No Trace Center for Outdoor Ethics, Old Dominion University and the State University of New York (SUNY) at Cortland collaborated to develop the PEAK Assessment Scale (PAS). Using the PAS, the purpose of this study was to measure the effect of the PEAK program on children's knowledge of Leave No Trace following participation in a oneday PEAK program. To achieve these goals the following research question was used to guide this study:

Do children's scores on the PAS increase following participation in the PEAK program?

\section{Literature Review}

With rapidly expanding technology and a decline in time spent out-of-doors, children are becoming increasingly disconnected from nature (Louv, 2008; The Outdoor Foundation, 2010). According to Davis (1998), today's children are learning how to be "avid consumers, to value the trivial, to be instantly gratified and expect entertainment from their toys, computers and parents rather than from nature" (p. 117). Moreover, research has demonstrated the mental and physical benefits children experience when they spend time in nature and participate in environmental and outdoor education opportunities (Berman, Jonides, \& Kaplan, 2008). Other studies have reported that children have a better quality of life when they are actively engaged and play in natural places (Pretty, Angus, Bain, Barton, Gladwell, Hine, et al., 2009). Godbey (2009) reports that getting children outdoors and active in nature can help them with major health issues such as obesity and attention-deficit disorder. A 2010 report published by the National Recreation and Parks Association, indicated that individuals who have access to and use of natural green spaces tend to show
.... better cognitive functioning; more proactive, more effective patterns of life functioning; more self-discipline and more impulse control; greater mental health overall; and greater resilience in response to stressful life events. Less access to nature is linked to exacerbated attention deficit/hyperactivity disorder symptoms, more sadness and higher rates of clinical depression. People with less access to nature are more prone to stress and anxiety, as reflected not only individuals' self-report but also measures of pulse rate, blood pressure, and stress-related patterns of nervous system and endocrine system anxiety, as well as physician- diagnosed anxiety disorders (Kuo, 2010, p. 3).

The report also described that access to green spaces supports several physical components, which include: 
.... higher levels of physical activity, improve[s] immune system functioning, help[s] diabetics achieve healthier blood glucose levels, and improve[s] functional health status and independent living skills among older adults. By contrast, environments with less green are associated with greater rates of childhood obesity; higher rates of 15 out of 24 categories of physiciandiagnosed diseases, including cardiovascular diseases; and higher rates of mortality in younger and older adults (Kuo, 2010, p. 3).

The rising disconnect from natural environments is not only negatively impacting the physical and mental health of children, it is also contributing to a lack of stewardship for the environment among young people. In a longitudinal (1976 to 2005) study measuring adolescents' concern for the environment, Wray-Lake, Flanagan, and Osgood (2008) found that taking on personal responsibility for the environment, or pro-environmental behavior, has declined in adolescents over the years. The researchers argue that with the rise in materialism and consumerism in the U.S., there has also been a decline in knowledge regarding the scarcity of our natural resources. Wray-Lake, Flanagan, and Osgood (2008) claim this decline in knowledge about the environment has led to a decreased concern for the environment among youth. Rather than viewing it as their personal responsibility, youth feel responsibility for the environment should fall to the country's leadership instead of one's self. The 30 years of data collected in this study also indicated when the government takes more responsibility for the environment, youth tend to feel they should do more. This leads to the belief that it takes a collective effort in leadership, the school system, parents, and organizations to increase awareness about how human impact on our eco-systems affects natural resources.

The urgent need for society to address climate change (IPCC, 2007) coupled with declines in young people's concerns about the environment in general, and limited knowledge and investment in climate change in particular (Hamilton College National Youth Polls, 2007), call for educational and programmatic interventions to promote environmental consciousness in youth (as cited in Wray-Lake, Flanagan, \& Osgood, 2008, p. 23).

With the correct training, education, guidance, and life-long standards and attitudes, children's concern for the environment can deepen and ultimately lead to more pro-environmental behaviors.

Although getting children in nature is crucial to child development and building future environmental advocates, history shows that increased use of recreational and natural areas increases the probability of negatives impacts on the environment (Marion, \& Reid, 2007). With an expanded effort to get youth into the out-of-doors, it is crucial to provide educational programs (e.g., PEAK) to teach children the low-impact skills necessary to help sustain the natural environment.

\section{Leave No Trace and Promoting Environmental Education in Children}

In 2001, Leave No Trace recognized the value of educating children about ways in which they could minimize their impact while still enjoying the out of doors. In partnership with Recreation Equipment, Inc. (REI) the Promoting Environmental Awareness in Kids (PEAK) program was created and designed to teach children about the environment and how to recreate responsibly in the out-of-doors (Leave No Trace, 2010). The seven 'kid friendly' principles, based on the original seven principles of Leave No Trace, include: 
1. Know Before You Go, teaching children the skills necessary to prepare in advance prior to recreating outside;

2. Choose the Right Path, teaching techniques and knowledge about how to protect different environments by making decisions that have less impact on the environment;

3. Trash Your Trash, teaching skills necessary to keep the environment clean from litter and other waste;

4. Leave What You Find, teaching the importance of leaving artifacts and other natural items behind for the next person to enjoy;

5. Be Careful With Fire, teaching the techniques for making responsible decisions about how, when, and where to have a fire;

6. Respect Wildlife, teaching children how our behavior can affect wildlife and learn how to appreciate wildlife from a distance; and

7. Be Kind To Other Visitors, teaching kids how to be respectful of others (Leave No Trace, 2010).

The primary goals of the PEAK program are to

a) increase awareness of Leave No Trace,

b) promote stewardship of public lands,

c) meet the demands of diverse youth populations, and

d) to have fun (www.Int.org).

To meet these goals, Leave No Trace and REI created the PEAK training program to provide educators with training materials on how to use the PEAK Pack, a pre-packaged set of lesson plans for teaching the seven principles. The lessons are designed to be active and hands-on. When learning is enhanced and constructed through active hands-on experience, there is a greater likelihood that the material is retained, and thus, a greater chance of new behaviors being adopted. By increasing the retention rate of the low-impact skills through active learning, an increased sense of care for the environment can result leading to more pro-environmental behaviors. (Adkins, \& Simmons, 2002; Eggen, \& Kauchak, 2004; Gilbertson, Bates, McLaughin, \& Ewert, 2006). With six ready-to-use activities, educators, camp counselors, and other educators can use the PEAK Pack to teach youth how to act responsibly in nature and encourage stewardship for the natural world.

Intentional hands-on environmental programs, such as PEAK, are crucial to the development of pro-environmental attitudes and behaviors in children. With the disconnect between children and nature on the rise, there is a strong need to get children in the out-of-doors exploring, playing, and participating in purposeful environmental education programs that can enhance their physical and mental well-being. The literature also indicates it is important to foster proenvironmental behaviors and attitudes in children at a young age to increase the chances that they will grow to become future environmental stewards. As stated earlier, the goals of the PEAK program are to increase knowledge about the seven Leave No Trace principles, increase low-impact skills, and increase environmental stewardship in children. This study was designed to assess the effectiveness of a one-day PEAK program on elementary school students knowledge of Leave No Trace.

\section{Method}

Student enrolled in a college outdoor education course developed an environmental curriculum for $5^{\text {th }}$ and $6^{\text {th }}$ graders of an elementary school in Central New York. Through this semester long 
course, the college students receive extensive training on how to develop high quality environmental and outdoor education programs for children. According to the syllabus:

Students enrolled in this course intend to teach, lead, facilitate, or interpret outdoor/environment related subject matter to people in school or other settings, as part of their career track. Students have a background or interest in nature and natural science topics/issues. Students will be expected to relate and apply information they have learned from a variety of natural sciences to projects and lessons (Shellman, 2011).

For the purpose of this study, in the spring of 2011, students enrolled in the course implemented the PEAK program as part of an assignment. Prior to delivering the program, the college students participated in a Leave No Trace workshop conducted by the researcher and faculty member to familiarize them with Leave No Trace and the PEAK program. The students were introduced to Leave No Trace, the seven low-impact principles and the PEAK curriculum. Throughout the semester, the college students developed lessons and activities that utilized the PEAK curriculum. Prior to the program facilitation, lesson plans and activities were reviewed for accuracy of content by the professor and teaching assistants. Feedback was provided to the student groups and all material was updated.

On separate days, the $5^{\text {th }}$ and $6^{\text {th }}$ graders were invited to participate in a day-long program at a local nature center. The students were divided into two separate groups based on grade level-the $5^{\text {th }}$ graders attended the program on day one and the $6^{\text {th }}$ graders attended the program on day two. They participated in a number of $P E A K$ activities that focused on the seven Leave No Trace principles: 1) Know Before You Go; 2) Choose the Right Path; 3) Trash Your Trash; 4) Leave What You Find; 5) Be Careful With Fire; 6) Respect Wildlife; and 7) Be Kind To Other Visitors. The goal of the program was to increase knowledge about the seven Leave No Trace principles and ultimately increase environmental stewardship among the children.

\section{Selection of Sample}

All fifth and sixth grade students at a local elementary school in Central New York were invited to participate in a one-day PEAK program at a local nature center as part of a nature-based field trip. College students enrolled in an environmental and outdoor education course facilitated the program. The program consisted of college students creating and teaching PEAK related activities to approximately 120 fifth and sixth grade students at a local nature center.

\section{Data Collection}

Data was collected in the classroom before and after participation in the PEAK program at the nature center. Participants were instructed that they were not required to participate in the study and could opt out at any time. The 32-item PEAK Assessment Scale (PAS) was administered prior to the program, within one or two days following the program and a third time eight months after the program. The PAS includes four items for each principle as well as an additional four items designed to measure general feelings about Leave No Trace and the natural environment. For instance, one of the items stated, "It's important to teach my friends and family about the Leave No Trace Principles." Response options ranged from "1" = strongly agree to "4" = strongly disagree. Upon creation of the PAS, all items were subjected to the Flesch-Kincaid (Kincaid, Fishburne, Rogers, \& Chissom, 1975) grade-level readability test. Convergent validity was tested (i.e., 5-item Affinity for Nature (AN) Scale, Ellis, \& Sibthorp, 2006). In addition, the Average Variance Extracted (AVE) was used to assess validity-related evidence based on the sample scores. The Cronbach's Alpha Reliability for each subscale fell 
between .61 and .77 (acceptable to good) and the Cronbach's alpha for the entire scale was .94. Results indicate the PAS is an effective unidimensional scale for assessing the PEAK Program (Miller, Shellman, Hill, Ramsing, \& Lawhon, 2012).

Prior to participating in the one-day PEAK program at the nature center, the $5^{\text {th }}$ and $6^{\text {th }}$ graders were asked to complete the pre-test PAS. The questionnaire administrator, who was the students' classroom teacher, asked the students to read each statement carefully and to complete the questionnaires as honestly as possible. Completed questionnaires were collected by the classroom teacher and submitted to the researchers.

Following participation in the PEAK program, a post-test was administered to the students one or two days after the program. The questionnaires were again administered and collected by the students' classroom teacher and returned to the researchers. Eight months following the program the PAS was again administered by the classroom teacher and collected by the researchers to determine the longitudinal effects of the program. To measure the effectiveness of the PEAK program, an ANOVA was conducted to determine if there was a significant difference in scores on the PAS from pre to post-test. MANOVA was used to determine if there was a significant difference after the 8-month follow-up.

\section{Results}

A total of 102 questionnaires were collected. After the pre-test and post-test questionnaires were matched and the data were cleaned and screened for outliers, a total of 71 usable questionnaires were used in further analysis. All data were entered into Microsoft Excel and SPSS 17.0 for analysis. Study participants ranged in age from 10 to 13 with a mean age of 11.27 years $(S D=70)$, and included 41 females $(57 \%)$ and 30 males (42\%). As mentioned, a follow-up post-test was administered eight months after the program to determine longitudinal effects of the PEAK program. Since the sixth grade population from the original pre-post-test had moved on to middle school only the current sixth graders $\left(5^{\text {th }}\right.$ graders at the time of the original data collection) were asked to complete the follow-up post-test. A total of 23 matched questionnaires were obtained from the follow-up post-test.

To determine if there was a significant effect from the pre- and post-test, an analysis of variance (ANOVA) was conducted. Results revealed a significant increase between the pre-test $(\mathrm{M}=3.41, \mathrm{SD}=.34)$ and the post-test $(\mathrm{M}=3.61, \mathrm{SD}=.36)$ with the post-test scores being significantly higher, $F(1,140)=11.15, \mathrm{p}<.01$ (see Figure 1 ). 
Figure 1

Mean scores of the pre- and post-test data collection intervals, depicting and increase in knowledge after participation in the PEAK program

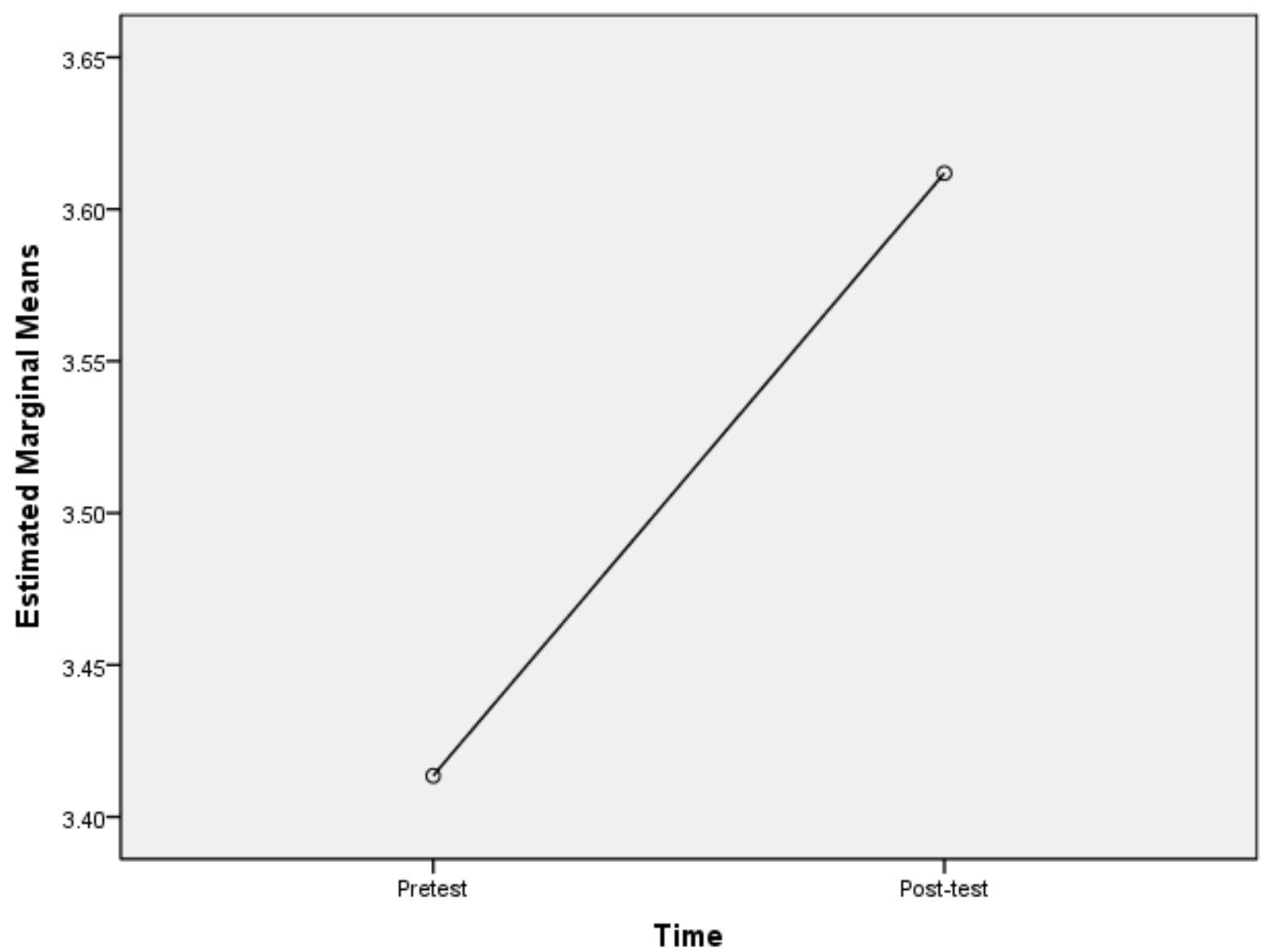

To determine if there was a significant effect from the pre- post- and 8-month post-test, a MANOVA was conducted based on the response rate of 23 matched questionnaires at the 8month post-test collection. No significant difference was found on this subset of the sample between the pre-test $(\mathrm{M}=3.48, \mathrm{SD}=.35)$, post-test $(\mathrm{M}=3.63, \mathrm{SD}=.35)$, and 8-month posttest $(M=3.38, S D=.41), F(2,66)=2.50, p=.09$. The 8-month post-test indicated a drop, though not statistically significant, below the base-line level of the pre-test (see Figure 2). 
Figure 2

Mean scores of the pre-, post-, and 8-month post-test data collection intervals, depicting a decrease in knowledge over time after participation in the PEAK program

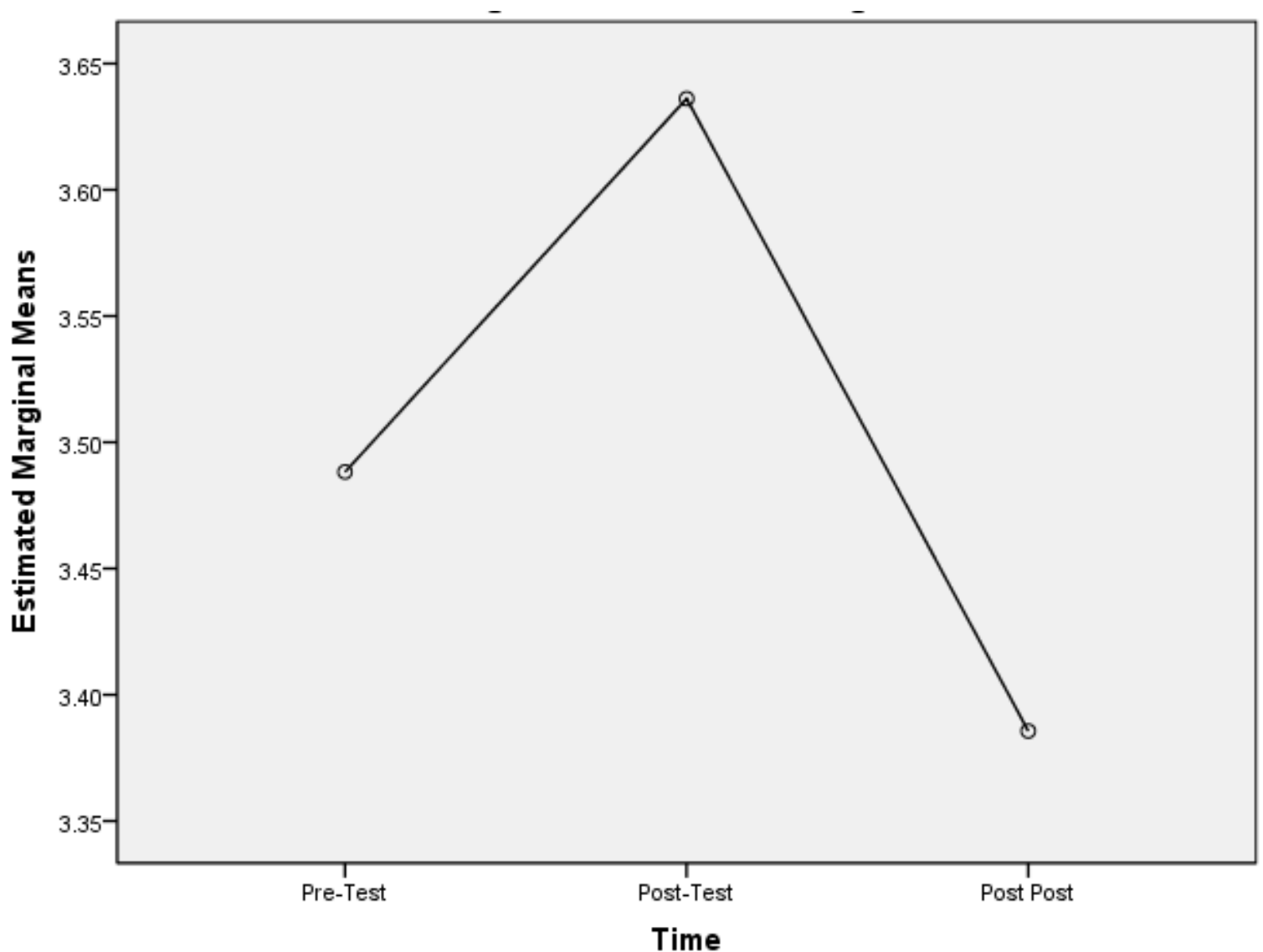

Since an option of "Don't Know" was included on the PAS, a comparison of the number of times this option was chosen between the pre- and post-test was conducted. Participants chose "Don't Know" 201 times in the pre-test, whereas participants only chose "Don't Know" 99 times in the post test, indicating knowledge was gained after participation in the program. When a comparison was conducted for the 8-month follow-up sample, out of 23 respondents, participants chose "Don't Know" 57 times in the pre-test, 38 times in the post-test, and 34 times in the 8-month follow-up. As stated before, from the pre- to post-test, there was a decrease in the number of times "Don't Know" was chosen, suggesting an increase in knowledge about Leave No Trace.

\section{Discussion}

Results of a previous study indicate that the 32-item PEAK Assessment Scale (PAS) is a valid and reliable instrument for assessing the PEAK program (Miller, Shellman, Hill, Ramsing, \& Lawhon, 2012). Results of this study suggest the PEAK program effective at increasing children's knowledge of the Leave Know Trace principles. Through this study, the PEAK program did have an immediate positive effect on children's knowledge of the Leave Know Trace principles and their understanding of the appropriate decisions and actions to take to follow those principles. However, retention of that knowledge appeared to decrease over time, suggesting that in order to effectively establish and promote environmental stewardship in youth, more extensive and 
pro-longed exposure may be necessary. As Witt and Caldwell (2005) stated, "program sustainability is important to the success of the program" (p. 20). Assessing the PEAK program's effectiveness is important for understanding its strengths as well as ways in which the program may be enhanced, such as offering multiple sessions over a period of time, though we recognize that this may not be practical in some cases. This study has shown that there are significant short-term effects so offering the PEAK program shortly before a school field trip might help children put their new knowledge into practice. To meet the goals of Leave No Trace and continue development and improvement of the PEAK program, additional research in this area is required. It will likely take more than a one-day program exposing youth to nature to change their feelings towards the environment.

\section{Limitations}

Limitations associated with the study include the use of a convenience sample and selfreporting. By asking fifth and sixth graders to reveal personal behaviors or feelings about the Leave No Trace principles, they may respond in what is believed to be a socially desirable manner. With the PAS being administered in the classroom, children may strive for social desirability and want to answer the items based on what they think is right, not necessarily report what they feel or how they would actually behave. Another issue with self-reporting includes the fact that participants in the PEAK program may not necessarily remember the material they learned, and simply circle something to avoid leaving an item blank.

\section{Conclusions}

The youth of today are tomorrow's adult outdoor stewards - the advocates, enthusiasts and conservationists charged with protecting our natural resources. However, there has been a paradigm shift regarding children's interest in the outdoors ultimately leading to their disconnect with the natural environment. More than any time in history, our children are provided a litany of choices and opportunities that invariably are keeping them indoors (Louv, 2008). Fortunately, there are effective initiatives such as the PEAK program that are providing a strong foundation for our children to learn about their role as stewards of our natural resources. Evidence obtained in this study indicate the PEAK program is an effective approach for teaching children the Leave No Trace principles - critical for teaching future generations how to recreate responsibly in the out-of-doors.

\section{References}

Adkins, C., \& Simmons, B. (2002). Outdoor, experiential and environmental education: Converging or diverging approaches? ERIC Digest.

Berman, M., Jonides, J., \& Kaplan, S. (2008). The cognitive benefits of interacting with nature. Psychological Science, 19(12), 1207-1212.

Davis, J. (1998). Young children, environmental education, and the future. Early Childhood Education Journal, 26(2), 117-123.

Eggen, P., \& Kauchak, D. (2004). Educational psychology: Windows on classrooms. (6th ed.). New Jersey: Person Education, Inc. 
Ellis, G., \& Sibthorp, J. (2006). Development and validation of a batter of age appropriate measures for camper outcomes. Technical report for the American Camp Association.

Gilbertson, K., Bates, T., McLaughin, T., \& Ewert, A. (2006). Outdoor education: Methods and strategies. Champaign, IL: Human Kinetics.

Godbey, G. (2009). Outdoor recreation, health, and wellness: Understanding and enhancing the relationship. Retrieved from Outdoor Resources Review Group - Resources for the Future Background Study: http://www.rff.org/Pages/default.aspx.

Hamilton College National Youth Polls. (2007). Climate change and environmental issues poll. Retrieved December 10, 2013 from http://www.hamilton.edu/news/polls/Climate/.

Intergovernmental Panel on Climate Change (IPCC). (2007). Climate change 2007. Retrieved December 10, 2013 from http://www.ipcc.ch/.

Kincaid, J.P., Fishburne, R.P., Jr., Rogers, R.L., \& Chissom, B.S. (1975). Derivation of new readability formulas (Automated Readability Index, Fog Count and Flesch Reading Ease Formula) for Navy enlisted personnel, Research Branch Report 8-75. Millington, TN: Naval Technical Training, U.S. Naval Air Station, Memphis, TN.

Kuo, F. (2010). Parks and other green environments: Essential components of a healthy human habitat. Retrieved from National Recreation and Park Association website:

http://www.nrpa.org/uploadedFiles/nrpa.org/Publications and Research/Research/Papers/Ming Kuo-Summary.PDF.

Leave No Trace Center for Outdoor Ethics. Promoting environmental awareness in kids (PEAK). (2010, January 5). Retrieved from http://Int.org/programs/peak.php.

Louv, R. (2008). Last child in the woods: Saving our children from nature-deficit disorder (2nd ed.). New York: Woodman Publishing Company, Inc.

Marion, J.L., \& Reid, S.E. (2007). Minimizing visitor impacts to protected areas: The Efficacy of low impact education programs. Journal of Sustainable Tourism. 15(1), 5-27.

Miller, J., Shellman, A., Hill, E., Ramsing, R., \& Lawhon, B. (2012). The development and validation of a new assessment scale: Measuring the effectiveness of the Leave No Trace PEAK program. In A. Ewert and F. Vernon, (Eds.), Proceedings From The Coalition for Education in the Outdoors: Vol. 12. Research in Outdoor Education. Bradford Woods, IN: Coalition for Education in the Outdoors.

Pretty, J., Anqus, C., Bain, M., Barton, J., Gladwell, V., Hine, R., Pilgrim, S., Sandercock, G., \& Sellens, M. (2009).Nature, childhood, health and life pathways. Interdisciplinary Centre for Environment and Society Occasional Paper 2009-02. University of Essex, UK. [on-line paper] Retrieved from http://www.essex.ac.uk/ces/occasionalpapers/Nature\%20Childhood\%20and\%20Health\%20iCE S\%200cc\%20Paper\%202009-2\%20FINAL.pdf.

The Outdoor Foundation. (2010). Special report on youth: The next generation of outdoor champions. Retrieved from http://www.outdoorfoundation.org/. 
Shellman, A. (2011). Syllabus for EDU/REC 462 Environmental and Outdoor Education. (Available from the Recreation, Parks, and Leisure Studies Department, PO Box 2000, Cortland, NY 13045).

Witt, P., \& Caldwell, L. (2005). 10 principles of youth development. In P. Witt \& L. Caldwell (Eds.), Recreation and youth development (pp. 3-23). State College, PA: Venture.

Wray-Lake, L., Flanagan, C.A., \& Osgood, D.W. (2008). Examining trends in Adolescent environmental attitudes, beliefs, and behaviors across three decades. The Network for Transitions to Adulthood: Working Paper.

(c) Copyright of Journal of Youth Development $\sim$ Bridging Research and Practice. Content may not be copied or emailed to multiple sites or posted to a listserv without copyright holder's express written permission. Contact Editor at: patricia.dawson@oregonstate.edu for details. However, users may print, download or email articles for individual use.

ISSN 2325-4009 (Print); ISSN 2325-4017 (Online) 


\section{Appendix}

PEAK Assessment Scale (PAS)

\section{Know Before You Go}

\begin{tabular}{|c|c|l|}
\hline & kb1 & It is important to plan before going on a trip. \\
\hline & kb9 & If I go on long walks, I bring water. \\
\hline & kb25 & When I play outside and its sunny, I wear sunscreen. \\
\hline kb33 & If it is cold outside, I try to dress for the weather. \\
\hline
\end{tabular}

\section{Choose the Right Path}

\begin{tabular}{|c|c|l|}
\hline & crp2 & I try to stick to the path, even if it is muddy. \\
\hline & crp10 & When I ride a bike, I stay on the correct path. \\
\hline & crp18 & Sitting on rocks causes less impact than sitting on grass. \\
\hline crp26 & When I go for walks, I try not to step on flowers. \\
\hline
\end{tabular}

\section{Trash Your Trash}

\begin{tabular}{|c|c|l|}
\hline & tt3 & I try to leave places I visit better than I found them. \\
\hline & $\mathrm{tt} 11$ & I bring my trash home if there is no trashcan. \\
\hline & $\mathrm{tt} 19$ & It is important to clean up after your pet. \\
\hline & $\mathrm{tt} 27$ & If I see a bottle, I will pick it up to recycle it. \\
\hline
\end{tabular}

\section{Leave What You Find}

\begin{tabular}{|l|c|l|}
\hline & Iwf4 & I leave flowers for others to enjoy. \\
\hline & Iwf12 & If I find an arrowhead, I leave it for others to see. \\
\hline & Iwf20 & I leave what I find so others can enjoy it. \\
\hline & Iwf35 & It is important to take care of historic places. \\
\hline
\end{tabular}

\section{Be Careful with Fire}

\begin{tabular}{|c|c|l|}
\hline & bcf5 & If my family goes camping, we use dead sticks from the ground to build fires. \\
\hline & bcf13 & I am careful with fire. \\
\hline & bcf21 & If using a fire, I put it out before I leave. \\
\hline & bcf29 & If I need to build a fire, I only do it when adults are around. \\
\hline
\end{tabular}

\section{Respect Wildifife}

\begin{tabular}{|c|c|l|}
\hline & rw6 & If I find a nest of baby birds, I watch it from a distance. \\
\hline & rw39 & I take pictures of wildlife to share with my family. \\
\hline & rw30 & I respect wildlife. \\
\hline & rw37 & If I find a nest of baby rabbits, I leave it alone. \\
\hline
\end{tabular}

\section{Be Kind to Others}

\begin{tabular}{|l|c|l|}
\hline & bk7 & If there are other kids on the playground, I share the swing set. \\
\hline & bk15 & I respect other visitors when I'm at the park. \\
\hline & bk23 & If go walking, I share the path with others. \\
\hline & bk38 & I am kind to other people. \\
General LNT Concepts \\
\hline & overall8 & It's important to take care of nature. \\
\hline & overall16 & I will try to minimize my impact on nature. \\
\hline & overall24 & I do my best to make good decisions when visiting natural areas. \\
\hline & overall32 & I want to share the Leave No Trace Principles with my friends. \\
\hline
\end{tabular}

